\title{
The present day genesis and evolution of cave minerals inside the Ojo de la Reina Cave (Naica Mine, Mexico)
}

\author{
Giovanni Badino ${ }^{1}$, José Maria Calaforra ${ }^{2}$, Paolo Forti ${ }^{3}$, Paolo Garofalo ${ }^{4}$ and Laura Sanna ${ }^{2}$
}

\begin{abstract}
:
Badino G., Calaforra J., Forti P., Garofalo P. and Sanna L. 2011. Minerogenesis in Ojo de la Reina Cave, Mexico. International Journal of Speleology, 40 (2), 125-131 Tampa, FL (USA). ISSN 0392-6672. DOI 10.5038/1827-806X.40.2.5

Ojo de la Reina is the first and the smallest cave intersected at the -290 level in the Naica Mine (Mexico), therefore it was the first cavity in which the lowering of temperature induced by mine ventilation caused condensation over crystals' surface since 2005 . The consequent dissolution of the gypsum crystals and subsequent condensed water evaporation lead to the deposition of several new minerals, among which some highly soluble $\mathrm{Mg} / \mathrm{Na}$ compounds (bloedite, epsomite, halite, hexahydrite, kieserite, starkeyite). The single available source of $\mathrm{Mg}$ and $\mathrm{Na}$ ions in this minerogenetic environment is represented by the huge fluid inclusions widespread within the crystals. The condensation occurs mainly along the widened principal exfoliation (010) planes, and allows to an easy and fast opening of the fluid inclusions that consequently drip Mg-rich fluids stored inside them. Finally the evaporation of the relatively small volumes of involved water allows to the development of the high soluble $\mathrm{Mg}$ and $\mathrm{Na}$ compounds.
\end{abstract}

Keywords: mineralogenesis, cave climate, geochemistry, fluid inclusions

Received 31 December 2010; Revised 2 February 2011; Accepted 5 March 2011

\section{INTRODUCTION}

The Naica caves and their amazing gypsum crystals were discovered almost a century ago inside a silver mine in the state of Chihuahua (Mexico) (Degoutin, 1912). Between 2000 and 2008, the mining activities at $-290 \mathrm{~m}$ level intercepted 4 small caves hosting the largest gypsum crystals in the world (Shagun, 2001; London, 2003) (Fig. 1). In the last couple of years these caves have been explored (Badino \& Forti, 2007) and their environment and giant gypsum crystals have been described by many investigators (Bernabei et al., 2007; García-Ruiz et al., 2007; Forti et al., 2008, 2009; Garofalo et al., 2010; Forti, 2010; Forti \& Sanna, 2010; Sanna et al., 2010).

The Ojo de la Reina Cave (Fig. 2) is the smallest of the four natural cavities currently known at the -290 m level of the Naica Mine and it was the first

${ }^{1}$ Dept of Physics, University of Torino, Via Pietro Giuria 1, 10125 Torino, Italy (badino@to.infn.it).

${ }^{2}$ Dept of Geological Sciences, University of Almeria, Water Resources \& Environmental Geology, University of Almeria, La Cañada de San Urbano s/n 04120 Almeria, Spain (jmcalaforra@ual.es).

${ }^{3}$ Italian Institute of Speleology, University of Bologna, Via Zamboni 67, 40126, Bologna, Italy (paolo.forti@unibo.it)

${ }^{4}$ Dept of Earth and Geological-Environmental Sciences, University of Bologna, Via Zamboni 67, 40126 Bologna, Italy (paolo.garofalo@unibo.it).

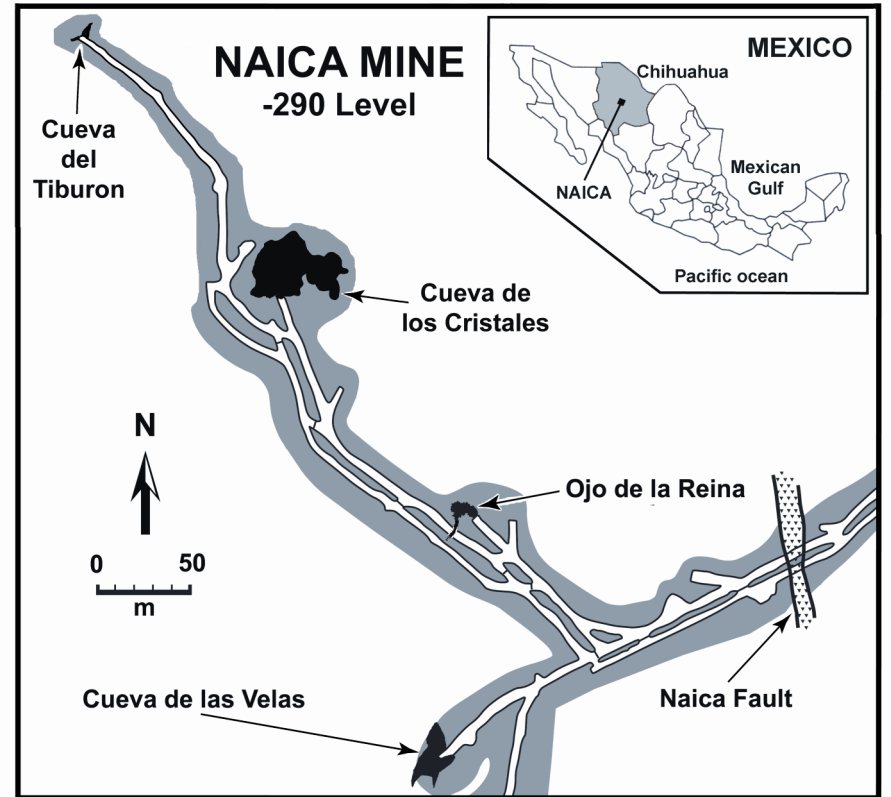

Fig. 1. Map of the $-290 \mathrm{~m}$ level of the Naica Mine with the four currently known caves.

intersected by exploitation activities. It consists of a narrow sub-vertical fracture parallel to the Naica fault, and it is totally filled with giant prismatic selenite crystals. Thus the hosting rock (dolostone and dolomitic limestone) is completely isolated from contact with the cave atmosphere by gypsum mineralization (Fig. 3). 


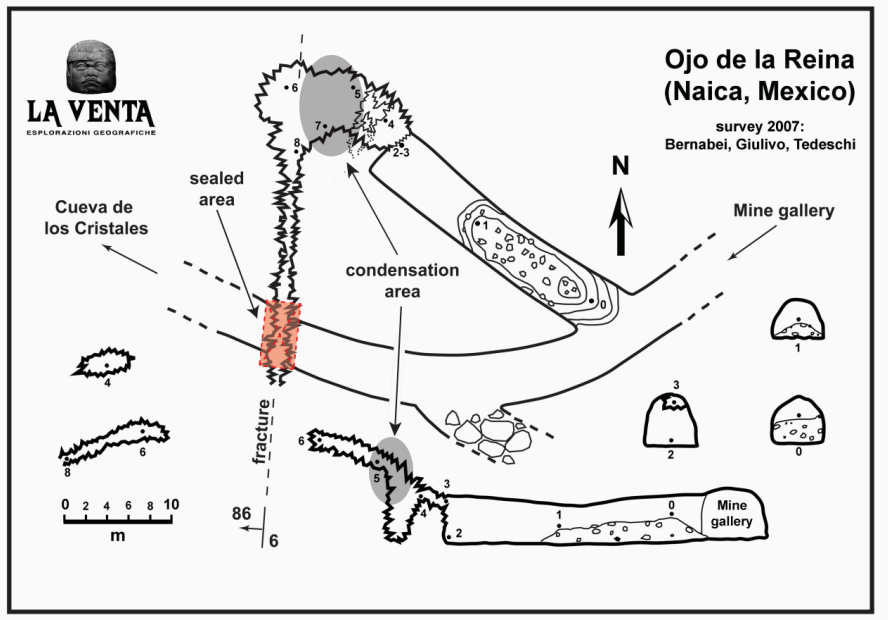

Fig. 2. Map of the Ojo de la Reina cave: the grey spot is the area in which the condensation is highest, while the pink rectangle is the area sealed by concrete.

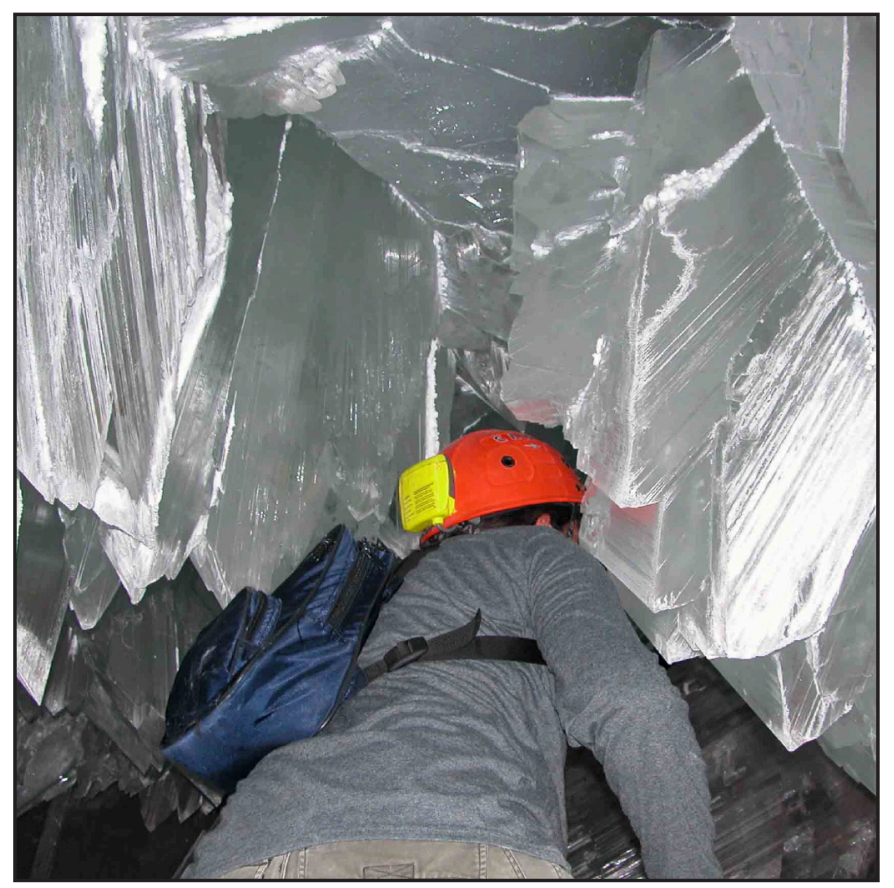

Fig. 3. A general view of the giant selenite crystals partially covered by secondary deposits.

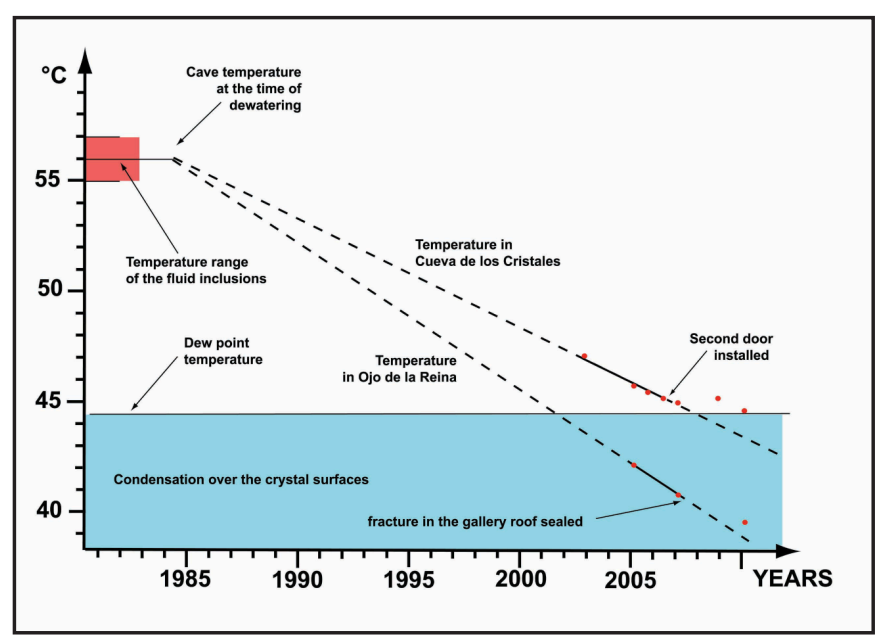

Fig. 4. The evolution of the temperature inside Cueva de los Cristales and Ojo de la Reina caves after their dewatering.
A direct connection of the main mine gallery allows for strong air circulation inside this cave, causing a temperature drop in its walls of some 0.6 ${ }^{\circ} \mathrm{C} /$ year. In 2005 the dew point was reached (Fig. 4) and a condensation process became quickly initiated in the upper part of the cavity. At this location the giant gypsum crystals started to rapidly dissolve and new mineral phases began to precipitate (Fig. 5). This process led to the development of relatively large white speleothems (flowstones, crusts, helictites, powders) (Fig. 6), most of which consist of calcium carbonate (calcite and aragonite) and minor gypsum.

In a few places on the floor, where dripping water collects in small depressions at the contact between two or more gypsum crystals, several other minerals - most of which extremely soluble - are forming (Forti et al., 2009) (Fig. 6D). In a mineralogical study of the Naica caves, during the 2008 expedition, a few speleothem samples were collected from this cave (Forti et al., 2009). Analyses of these samples showed that one fundamental factor for the development of some of the observed diagenetic minerals is the presence of large saline fluid inclusions inside the giant gypsum crystals.

\section{ENVIRONMENTAL EVOLUTION WITHIN THE OJO DE LA REINA CAVE}

Ojo de la Reina Cave was intersected in 2002 by underground mining, but previous mining activity caused it to be free of water in 1985 (personal communication from the geologic office of the Naica Mine). Before that time, the fluid temperature at the $-290 \mathrm{~m}$ level (obviously equal to that of the infilling water) was in the range of $48-56^{\circ} \mathrm{C}$ by a representative fluid inclusion record (Garofalo et al., 2010). The data gathered from the Ojo de la Reina gypsum crystals specifically refers to two different groups of cogenetic inclusions: (1) inclusions trapped along the growth planes of crystals (i.e., primary inclusions) and (2) inclusions close to the primary inclusions but entrapped along a microfracture crosscutting the growth planes (i.e., secondary inclusions). For the

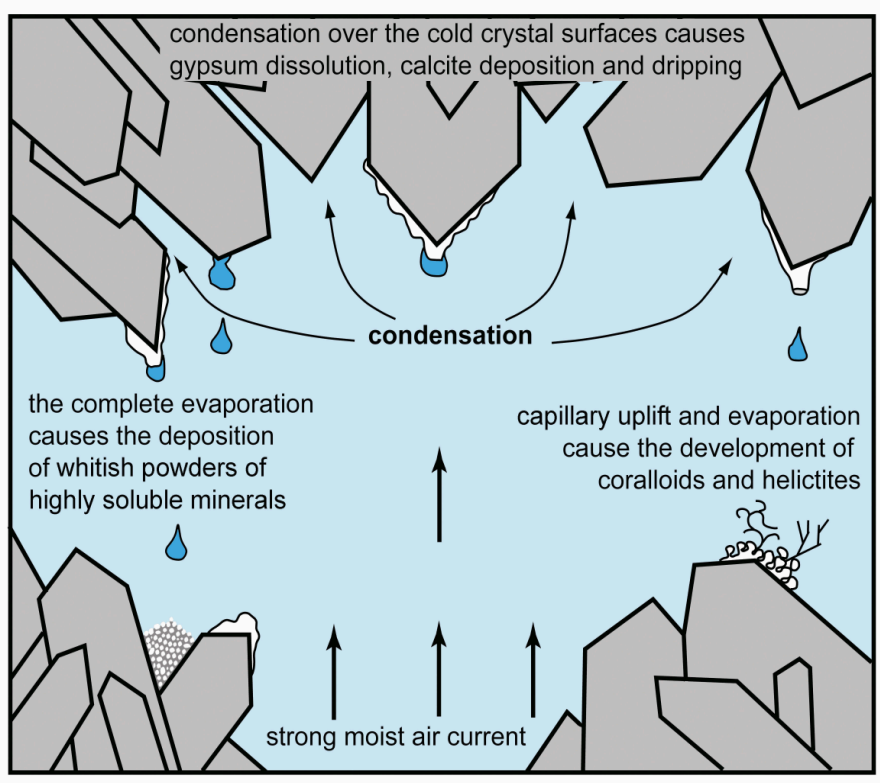

Fig. 5. Mechanism by which condensation/evaporation processes led to the evolution of new speleothems. 

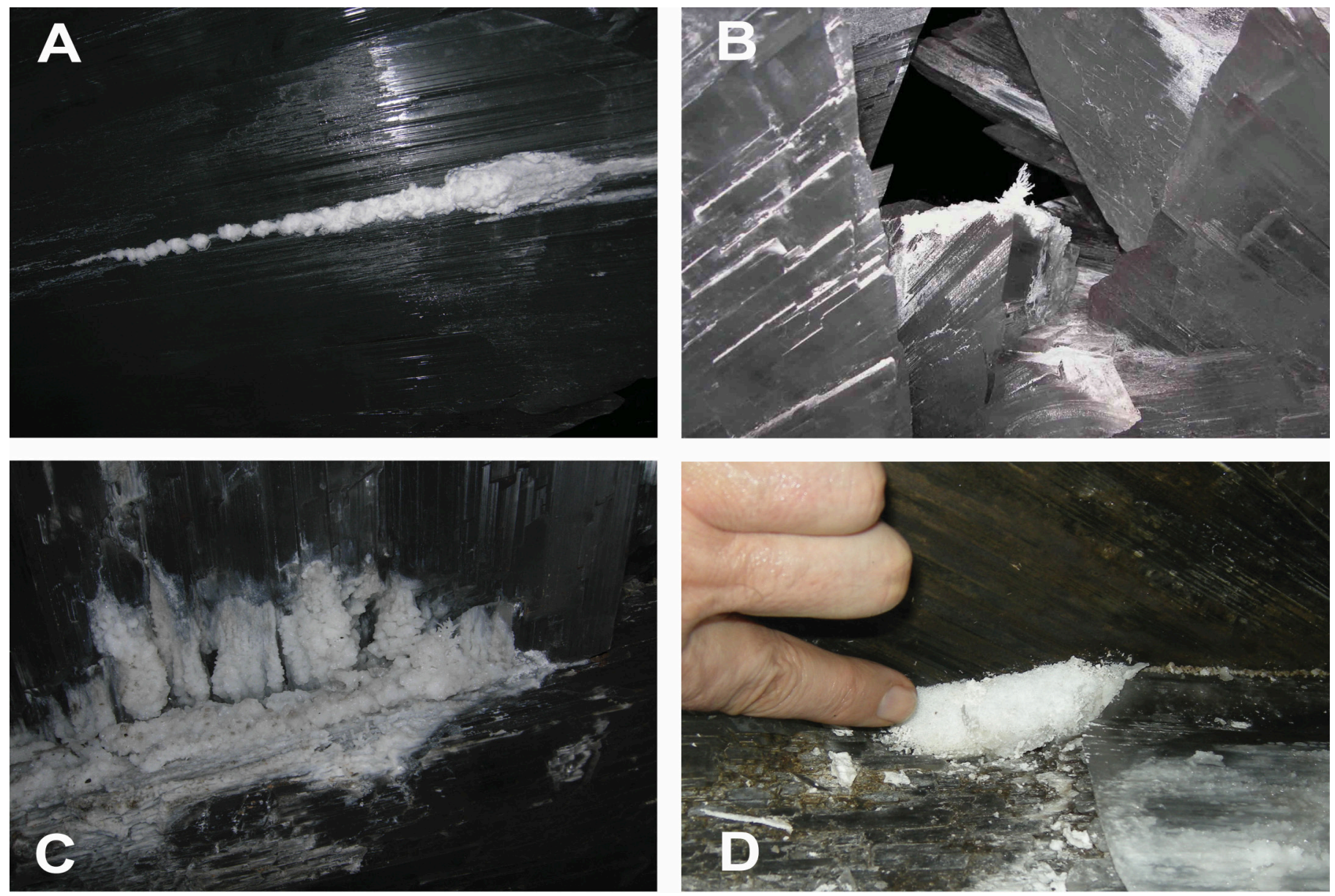

Fig. 6. Different types of cave formations developed inside Ojo de la Reina after the dew point was reached: A: calcite/gypsum crust along a 010 plane; B: a gypsum helictite; C: calcite popcorn; D: powder composed of an admixture of very soluble Mg/Na compounds.

primary inclusions, Garofalo et al. (2010) determined a bulk (equivalent) salinity of $3.4 \pm 0.3$ eq. wt $\% \mathrm{NaCl}$ (Fig. 7A), and for the secondary inclusions a total homogeneization temperature (Fig. 7B) of $55 \pm 2{ }^{\circ} \mathrm{C}$ was obtained. These narrow intervals of bulk equivalent salinity and total homogeneization temperatures demonstrate that post-entrapment modifications do not significantly affect the data (Bodnar, 2003), and therefore that the microthermometry properties are indeed those of a hypogene fluid from which the crystals precipitated.

However, after dewatering of the cave, the hypogene fluid from which the gypsum crystals precipitated did not control the cave temperature any longer, and warm vapour entering the air-filled cave was unable to fully compensate for the heat loss induced by mine ventilation. A temperature of $42.5^{\circ} \mathrm{C}$ was measured within the cave in 2005 (Fig. 4) when condensation was already active and at that time a few white crusts could be seen developing over the giant gypsum crystals. Since then, this condensation process has proceeded ever faster and in 2008 active dripping could be seen occurring from the tips of several megacrystals hanging from the roof.

In the same year the mine administration completed the artificial sealing of the large fracture interconnecting the main gallery of the mine and Ojo de la Reina Cave (Fig. 2), thus drastically reducing - but not completely stopping - air circulation and temperature lowering within the cave condensation still remains active, although it is far less vigorous.
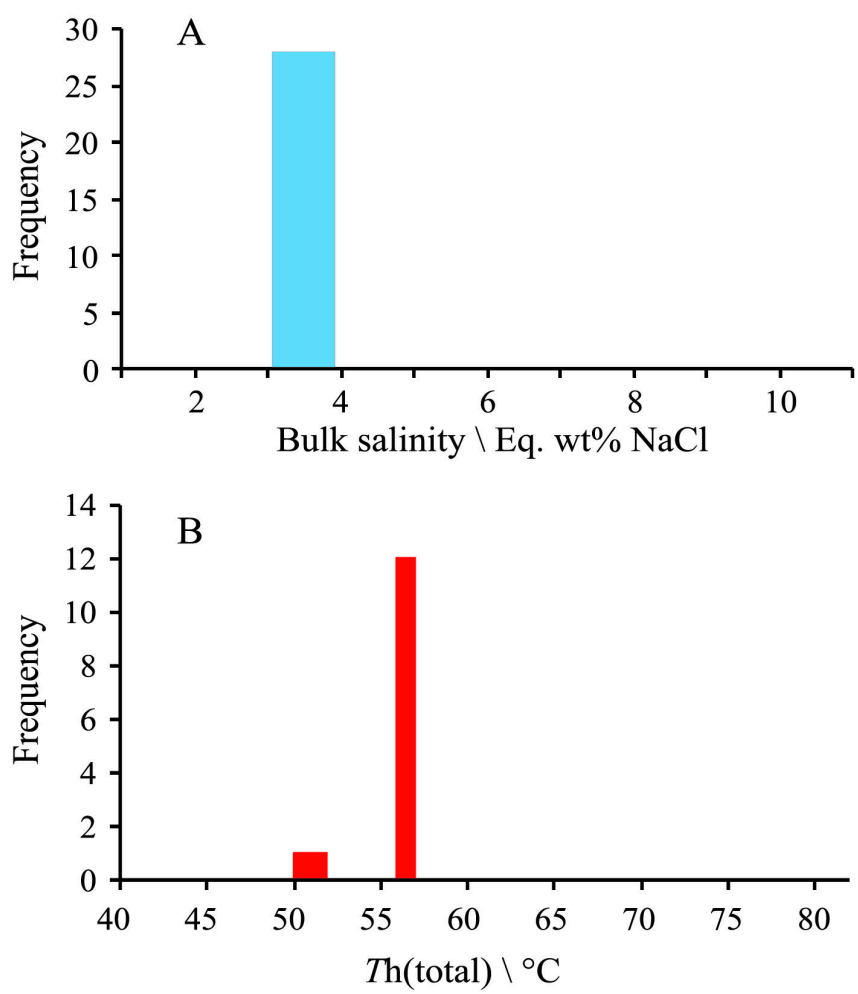

Fig.7. Bulk salinity (A) and total homogenization temperatures (Th) (B) determined for fluid inclusions in a gypsum crystal from Ojo de la Reina. Data refer to a primary growth plane of the crystal $(A)$ and to a secondary trail cutting the edge of the same crystal (B) (after Garofalo et al., 2010). 


\section{SPELEOTHEMS CURRENTLY FORMING IN OJO DE LA REINA CAVE}

When condensation processes started the first visible chemical deposits were thin white accumulations located directly along the 010 planes of the giant gypsum crystals (Fig. 6A). Later, as condensation increased, a gravity-controlled water film flowed along crystal faces, allowing for the evolution of thicker and larger crusts that covered wider parts of the crystals. When dripping started, small white speleothems began to form from the tips of the crystals and white coralloids and helictites began growing on the floor (Fig. 6B). A few of these speleothems consist of pure gypsum while most of them are an admixture of small-elongated gypsum crystals and calcium carbonate grains (mainly calcite with some aragonite). The coralloids are pure calcite (Fig. 6C).

If the presence of secondary gypsum crystals is only the consequence of the evaporation of condensed water over the giant crystals, the evolution of calcium carbonate occurs due to $\mathrm{CO}_{2}$ diffusion from the cave atmosphere into a solution with a relative high $\mathrm{Ca}^{2+}$ concentration. This process, as evidenced by studies performed at the $-590 \mathrm{~m}$ horizon of the Naica Mine (Forti et al., 2008), causes the precipitation of calcite and/or aragonite instead of gypsum, providing that the boundary conditions of temperature, chemical composition of the solution, and degree of supersaturation) are met.

At the end of 2008, few small pools were observed on the floor in the upper part of the cave (grey spot in Fig. 2). These consist of small depressions at the contact between two or more prismatic gypsum crystals. Two or three of the pools were filled with no more than $10-20 \mathrm{~cm}^{3}$ of solution, whereas several others contained a white powder (Fig. 6D) deposited by the total evaporation of the formerly contained solution.

The external aspect of these powders, as well as their taste, suggested that they were composed of a highly soluble Mg-salt like epsomite. Thus, to avoid possible dehydration while carrying them to the lab for analyses, they were sealed in waterproof test-tubes while still inside the cave, and only opened at the time the analyses were performed.

Analysis of the powders revealed an unexpected mineralogical richness consisting of aggregates of six different very soluble minerals, most of them sulphates (Fig. 8): blödite $\left[\mathrm{Na}_{2} \mathrm{Mg}\left(\mathrm{SO}_{4}\right)_{2} \cdot 4 \mathrm{H}_{2} \mathrm{O}\right]$, epsomite $\left(\mathrm{MgSO}_{4} \cdot 7 \mathrm{H}_{2} \mathrm{O}\right)$, hexahydrite $\left(\mathrm{MgSO}_{4} \cdot 6 \mathrm{H}_{2} \mathrm{O}\right)$, kieserite $\left(\mathrm{MgSO}_{4} \cdot \mathrm{H}_{2} \mathrm{O}\right)$, starkeyite $\left(\mathrm{MgSO}_{4} \cdot 4 \mathrm{H}_{2} \mathrm{O}\right)$, together with minor gypsum and halite (Forti et al., 2009).

The probability that the simultaneous presence of these four Mg-sulphates with different hydration coefficients was induced by degradation of samples during transport to the lab is considered unlikely because of the careful containment method of sampling, storing, and transporting to the laboratory. It is thus reasonable to infer that they precipitated simultaneously inside the cavity. The environmental conditions inside the Ojo de La Reina Cave allow for fast evaporation and thus different stages of dehydration under the environmental conditions could have been easily reached in the different small
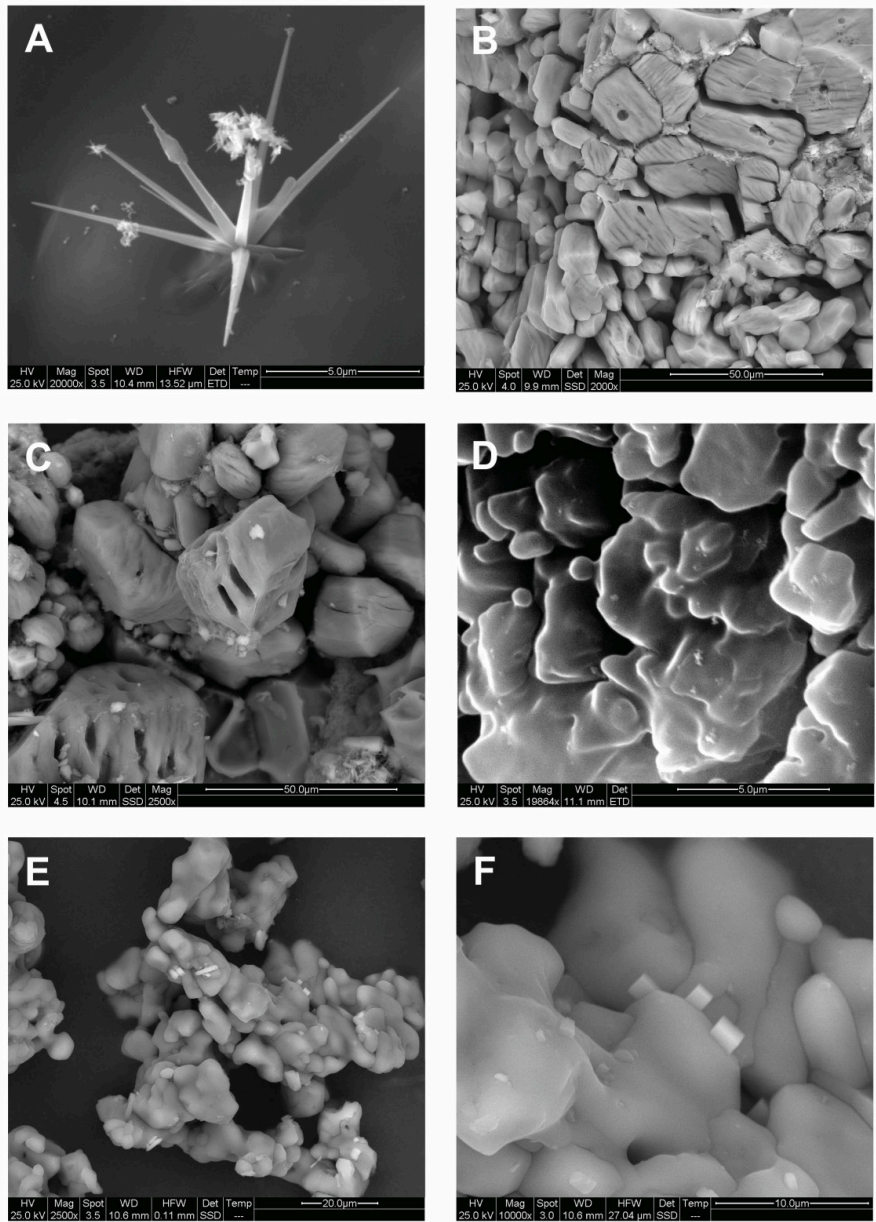

Fig. 8. SEM images of minerals present in the white powder (Laboratorio Centro Interdipartimentale Grandi Strumenti of Modena \& Reggio Emilia University): A: gypsum; B: epsomite; C: blödite; D: hexahydrite; E: starkeyite; F: halite.

pools. To support this interpretation, in some pools at the time of sampling only water was present, while other pools hosted wet powder or were completely dry.

The genesis of these different hydration minerals requires a mother solution with relatively high magnesium and sodium content that is impossible to justify by means of the simple condensation/ dissolution processes occurring over the external surfaces of the giant selenite crystals. Theoretically, magnesium may be leached from the dolomite-rich rock in which the cave is carved, but as discussed before, all the walls and ceiling of the Ojo de la Reina Cave are completely covered by the giant gypsum crystals and no exposures of the hosting dolomitic rock are visible. Moreover, even if the rock may hypothetically supply the magnesium ions, this is not the case for sodium and chlorine. The only available solution with a chemical composition similar to the minerals observed in the powders is that trapped in the fluid inclusions of the gypsum crystals.

A record made of LA-ICP-MS analyses of single fluid inclusions entrapped within the gypsum crystals of Ojo de la Reina and Cueva de los Cristales has recently shown that the chemical composition of the -290 m level cave fluids was chemically homogeneous, the main components in solution being $\mathrm{Mg}, \mathrm{Na}$, $\mathrm{K}$, and $\mathrm{Sr}$ in addition to $\mathrm{Ca}$ and $\mathrm{S}$ (Garofalo et al., 2010). In particular, at Ojo de la Reina, 23 primary 
and co-genetic fluid inclusions showed similar concentrations of $\mathrm{Na}$ and $\mathrm{Mg}$ (average values about $3000 \mu \mathrm{g} / \mathrm{g}$ for both elements). These values, however, represent minimum concentrations in the Naica fluid, as LA-ICP-MS analyses of fluid inclusions from the shallow Cueva de las Espadas gave concentrations that are three times higher for $\mathrm{Mg}$ (about $9000 \mu \mathrm{g} / \mathrm{g}$ ) and 1.5 times higher for $\mathrm{Na}$ (about $4500 \mu \mathrm{g} / \mathrm{g}$ ). The bulk concentration of $\mathrm{Cl}$ in these high-salinity fluid inclusions was calculated as $34.8 \mathrm{~g} / 1$ to charge balance the concentration of metals and sulfate anions in this cave fluid (Briceño Prieto et al., 2007), which is equivalent to the typical $\mathrm{Cl}$ content of brines. The corresponding content at Ojo de la Reina and Cueva de los Cristales was instead a factor of three lower, i.e., in the order of $10 \mathrm{~g} / 1$. Because mixing between the shallow (Mg-rich) high-salinity cave fluid and the relatively more diluted deep fluid probably drove gypsum precipitation at Naica (Garofalo et al., 2010), it is highly likely that the bulk composition (and thus the concentration of individual fluid components) of the cave fluid varied gradually and systematically in time and space, between the maximum and minimum values reported above.

\section{THE ROLE OF CONDENSATION AND FLUID INCLUSIONS}

If the chemical evidence suggests that the mother solution for the minerals in the powders came from the same hypogene fluids that caused the huge fluid inclusions to be trapped within the crystals, how might these inclusions contribute to the dripping? And how might pools filled by dripping water go suddenly completely dry in the $100 \%$ humidity? To answer the first question it is necessary to analyse the physical properties of a liquid phase with respect to the gaseous one.

A liquid is essentially a transitional phase between solid and gas in which bond strength is intermediate between the two phases. The molecular interactions force each molecule to stay in close contact with the surroundings, but are not sufficiently strong to forbid the "sliding" of each particle onto the others. It is important to note that all around each molecule there are others with similar forces, the system is isotropic and molecules are able to move quite freely.

This symmetry is completely lost at the surface in a range of the same order of the intermolecular forces $(<1 \mathrm{~nm})$. In this small volume the molecules undergo an attractive force towards the liquid, thus a molecule requires energy to evaporate (latent enthalpy of evaporation). As a consequence, evaporation tends to cool the liquid, and some energy is also required to extend this critical region, i.e. at the surface (surface tension). The Clapeyron law describes the equilibrium pressure above a flat-water surface (Fletcher, 1969; Rogers et al., 1989). It is thus apparent that the attractive force (and thus the latent enthalpy of evaporation) depends on the number of molecules surrounding the molecule under evaporation, which in turn depends on the surface shape.

If the surface radius of curvature is much larger than the interaction lengths the surface may be considered flat, but corrections are due to the evaporation rate when dealing with a molecule on the surface of small droplets: in fact in this case the molecule is less bound to the liquid than on a flat surface and therefore its tendency to evaporate is stronger. Incidentally, it must be mentioned here that the very common presence of a stable aerosol (or haze) in a cave atmosphere is a direct evidence of supersaturation of moist air: in fact, in a simple "saturated" atmosphere, the droplets would quickly evaporate. The opposite is true for negative surfaces, like inside a gas bubble within the liquid or inside a moist micro-fracture within a solid. Here the evaporation tendency is lower than that for air with a water vapor pressure at equilibrium along a flat surface. Therefore it will condense onto a negative surface.

The equation connecting the $\mathrm{e}_{\mathrm{s}}$ (equilibrium pressure) on a flat surface and the $\mathrm{e}_{\mathrm{sr}}$ (equilibrium pressure on a droplet of radius $r$ at temperature T) is given by the Kelvin equation:

$$
e_{s r}=e_{s} \exp \left(\frac{2 \sigma M_{m o l . w}}{\rho_{w} R T} \frac{1}{r}\right)
$$

where $\sigma, M_{\text {mol.w }}$, and $\rho_{\mathrm{w}}$ are the water surface tension, molar mass, and density, respectively.

The Kelvin equation is useful also for a negative radius of curvature that is for a concave surface. In this case the surface needs a smaller vapor pressure to reach equilibrium and then it becomes a preferred condensing point for surrounding air in equilibrium with a flat surface. This means that small fissures tend to fill themselves with aggressive condensed water (Fig. 9).

This is exactly what has happened in the Ojo de la Reina Cave and it explains why the first white crusts were deposited along the main exfoliation planes (Fig. 10). As required by theory, condensation started just inside the slightly widened 010 planes before the supersaturation of the cave atmosphere caused water condensation over the flat surfaces of the gypsum crystals. Then the condensed water triggered the dissolution of gypsum along these planes and consequently their further widening (Fig. 10A).

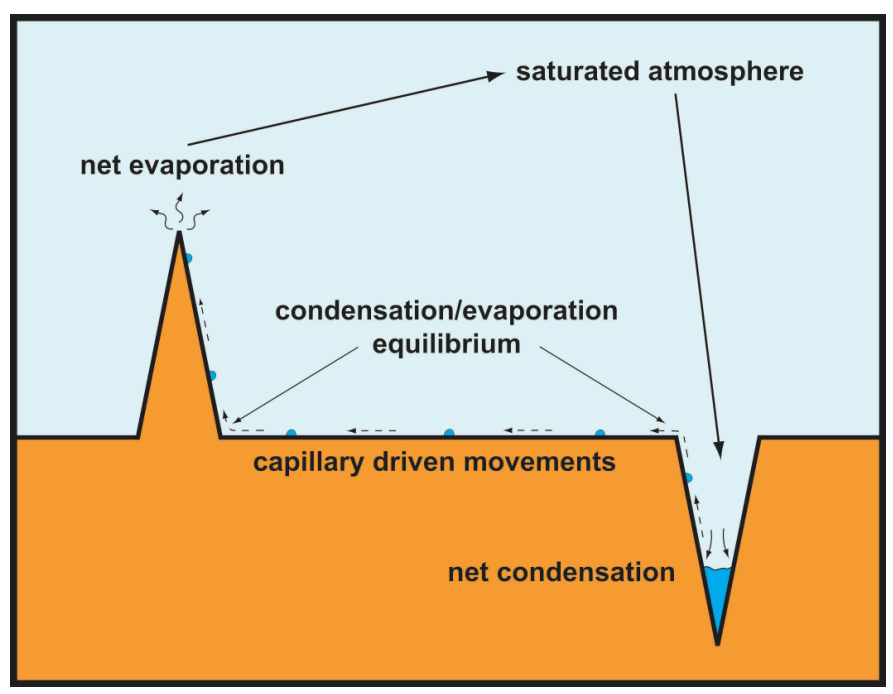

Fig. 9. The Kelvin law explains why a saturated atmosphere with respect to flat surfaces allows evaporation from protruding tips and condensation within narrow fractures. 
Nevertheless, during this stage, the supersaturation of the cave atmosphere was so low that it may easily have been turned into undersaturation when the forced ventilation inside the mine changed daily. Thus, the process was reversed and the solution inside the widened planes was driven by capillarity to evaporate on the crystal's external surface where the dissolved gypsum was forced? to deposit white crusts consisting of aggregates of acicular crystals right at the intersection of the exfoliation planes (Fig. 10B).

In the beginning the development of these linear crusts of acicular crystals were enhanced both by the phenomena of condensation/solubilization and evaporation/deposition; that is, by increasing the places in which condensation and capillary movement in both directions could occur. Later, when the gypsum crust became thick enough, both processes were progressively hindered. This fact explains why the great majority of the observed gypsum crusts along the 010 planes have almost the same thickness.

Most of the big fluid inclusions in the giant gypsum crystals are located along the 010 planes, the biggest of which may contain very large quantities of liquid (up to $50 \mathrm{~cm}^{3}$ and even more). Thus dissolution along cleavage planes may open from time to time and one of these large fluid inclusions will consequently flow along the widened plane and start to drip when reaching the outside surface (Fig. 10C). This will cause a quick accumulation of $\mathrm{Mg}-\mathrm{Na}$-Cl-rich solution within a depression at the contact between two or more gypsum crystals on the cave floor.

This scenario of pool filling also offers a reasonable answer to the second question: how might pools filled by dripping water go suddenly completely dry in the $100 \%$ humidity? Normal condensation over the ceiling is expected to cause relatively constant dripping from the tips of the gypsum crystals pointing downward. It is hard to imagine that such dripping may induce only few depressions to be filled by water while others remain completely dry. On the contrary, the occasional release of solution from one large fluid inclusion is perfectly compatible with the experimental evidence. A after the fluid inclusion has been completely emptied the pool may not be fed for a long interval of time. Thus, rapid evaporation off the pool water, induced by strong uplifting air currents, will deposit a series of different minerals, which carry the chemical composition of the mother solution.

In conclusion, the proposed mechanism not only justifies the presence of $\mathrm{Mg} / \mathrm{Na}$ minerals but also explains the presence of a few pools that are filled by solution, while others nearby may be completely dry.

\section{FINAL REMARKS}

The mining activities inside the Naica Mine triggered a relatively fast lowering of temperature inside all the caves at the $-290 \mathrm{~m}$ level. Ojo de la Reina, being the smallest cavity, was the first cave where the dew point was reached in 2005. Inside this cave the condensation/dissolution of the giant gypsum crystals led to the evolution of different speleothems, among which were some white powders consisting of an admixture of six very soluble $\mathrm{Mg} / \mathrm{Na}$ compounds.

Based on the experimental evidence, the genesis
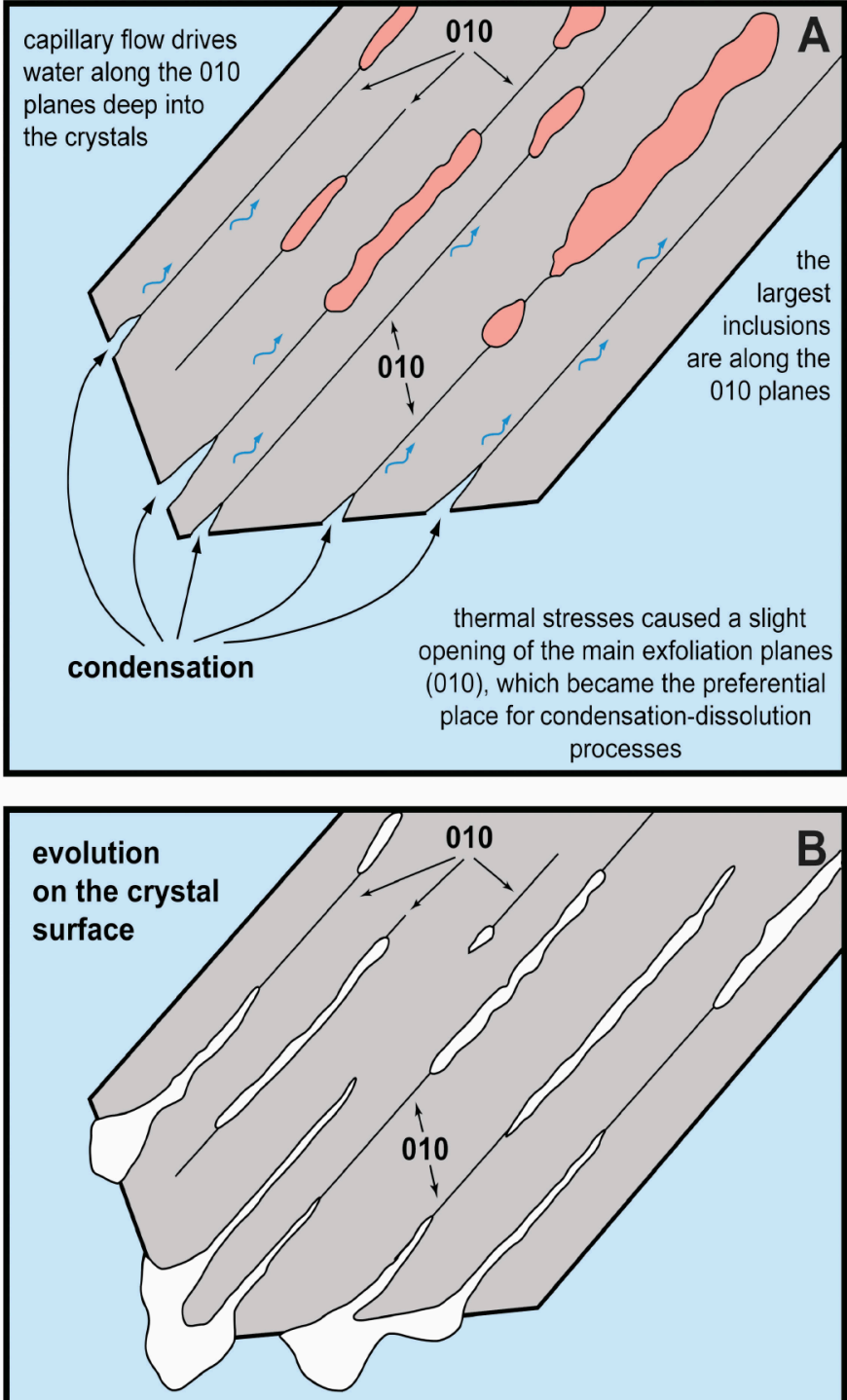

when water, seeping along the 010 planes, reaches the crystal surface, $\mathrm{CO}_{2}$ diffusion from the atmosphere into the solution and evaporation cause the deposition of white $\mathrm{CaCO}_{3}$ crusts

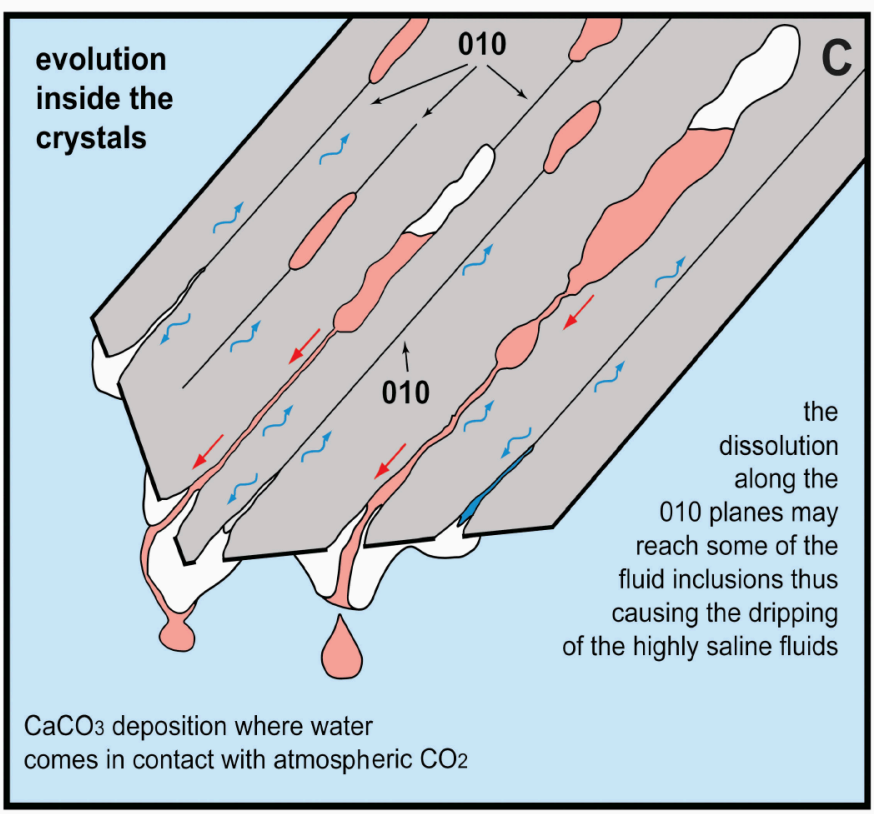

Fig. 10. The mechanisms by which contribution of fluid inclusions to dripping allow the precipitation of powder minerals. 
of these secondary minerals appears to be related to the large fluid inclusions trapped inside the gypsum crystals. The mechanism that allows the solution to escape from these fluid inclusions is strictly controlled by the transition of water from vapour to liquid state, which is enhanced just inside the slightly widened 010 cleavage planes of the gypsum crystals.

Thus, for the first time, the fundamental role played by evaporation/condensation processes have been applied not only to the shape of speleothems, but also to the control of their mineral composition

\section{ACKNOWLEDGMENTS}

The authors thanks the Peñoles Company for granting permission to perform the experimental work within the Naica mine, Speleoresearch \& Film, and La Venta Exploring team for the help given during the experimental study.

\section{REFERENCES}

Badino G. \& Forti P., 2007 - The Exploration of the Caves of the Giant Crystals (Naica, Mexico). NSS News, 65(2): 12-18.

Bernabei T., Forti P. \& Villasuso R., 2007 - A new type of gypsum crystal from Naica (Mexico). International Journal of Speleology, 36(1): 23-30.

Bodnar R.J., 2003 - Reequilibration of fluid inclusions. In: Samson I., Anderson A., \& Marshall D. (Eds.) - Fluid Inclusions: Analysis and Interpretation. Mineralogical Association of Canada, Short Course Series, 32: 213-230.

Briceño Prieto S., Martínez-Serrano R. G., Bernal J. P. \& Capaccioni B., 2007 - The geochemistry of Naica Waters and their links with the mineral assemblages. In: Forti P. (Eds), Book of Abstracts "Le Grotte di Naica: esplorazione, documentazione, ricerca" Bologna 15 Dicembre 2007: 35-36

Degoutin N., 1912 - Les grottes a cristaux de gypse de Naica. [The gypsum crystals of Naica caves]. Revista Sociedad Cientifica "Antonio Alzate", 32: 35-38.
Fletcher N. H., 1969 - The Physics of Rainclouds, Cambridge Univ. Press, 389 p.

Forti P., 2010 - Genesis and evolution of the caves in the Naica Mine (Chihuahua, Mexico). Zeitschrift für Geomorphologie, supplementary issue 54(2): 285-306.

Forti P., Sanna L., 2010 - The Naica Project: a multidisciplinary study of the largest gypsum crystal of the world. Episodes 33(1): 1-10.

Forti P., Galli E. \& Rossi A., 2008 - Il sistema GessoAnidrite-Calcite: nuovi dati dalle concrezioni della miniera di Naica (Messico). [Gypsum-AnhydriteCalcite system: new data from speleothems of Naica mine (Mexico)]. Memorie Istituto Italiano di Speleologia, Serie II, 19: 324-334.

Forti P., Galli E. \& Rossi A., 2009 - Minerogenesis in the Naica Caves (Chihuahua, Mexico). In: White W.B. (Ed.), Proceeding of the $15^{\text {th }}$ International Congress of Speleology, Kerrville Texas, USA, 1: 300-305.

García-Ruiz J.M., Villasuso R., Ayora C., Canals A. \& Otálora F., 2007 - The Formation of Gypsum Megacrystals. Geology, 35(4): 327-330.

Garofalo P.S., Fricker M., Günther D., Forti P., Mercuri A.M., Loreti M. \& Capaccioni B., 2010 - Climatic control on the formation of gigantic gypsum crystals within hypogenic caves (Naica mine, Mexico)? Earth and Planetary Science Letters, 289(3/4): 560-569.

London D., 2003 - New "Cave of the Crystals" at Naica, Chihuahua, Mexico. Earth Scientist Magazine, School of Geology and Geophysics, University of Oklahoma: 24-27.

Rogers R. \& Yau M.K., 1989 - Pergamon Press, 304 p. Sanna L., Saez F., Simonsen S., Constantin S. Calaforra J.M., Forti P., Lauritzen S.E., 2010 Uranium-series dating of gypsum speleothems: methodology and examples. International Journal of Speleology 39(1): 35-46.

Shagun C.L., 2001 - Naica's subterranean Marvels. NSS News, 59(6): 166-169. 